\title{
DOES A MINIMUM QUALITY STANDARD ALWAYS REDUCE THE PRICE OF HIGH QUALITY PRODUCTS?
}

\author{
by \\ John C. Panzar \\ University of Auckland \\ and \\ Ian Savage* \\ Northwestern University \\ June 20, 2011
}

Published in the Berkeley Electronic Journal of Economic

Analysis and Policy (Contributions), Volume 11(1), Article 39 (January 2011)

\begin{abstract}
This paper investigates the standard finding that instituting a minimum quality standard within a vertically differentiated market unambiguously benefits consumers of high quality products. A competitive model is specified in which random cost shocks lead some firms to cheat in equilibrium on their reputation for high quality. When cheating occurs, instituting or raising the level of a minimum standard can lead to the price of high quality products either increasing or decreasing. The effect of a minimum quality standard on the price of high quality products becomes an empirical rather than a theoretical issue.
\end{abstract}

Keywords: reputation, cheating, product quality, minimum quality standard

JEL Codes: L15, D21, D81

\footnotetext{
* Corresponding Author: Department of Economics, Northwestern University, 2001 Sheridan Road, Evanston IL 60208, USA. E-mail: ipsavage@northwestern.edu.
} 


\section{INTRODUCTION}

Many "experience goods" (Nelson, 1970) are susceptible to some firms "cheating" on quality. By this we mean that a firm with a reputation for providing high quality goods or services suddenly and unexpectedly reduces the quality of their product yet still charges a price consistent with high quality. Many types of markets are susceptible to cheating. Examples include restaurants (analyzed by Jin and Leslie, 2003, 2009), personal services such as dry cleaners and beauty salons, auto repair shops, transportation services such as limousines and truck lines, home maintenance services and, more recently, the sale of collectibles and other goods through Internet auction sites (Jin and Kato, 2006).

There is an ongoing literature that started in the early 1980s describing how firms may establish and destroy a reputation for providing high quality. However, a feature of much of this literature is that, in equilibrium, prices are such that firms do not have any incentive to cheat. Because, in practice, consumers experience cheating reasonably frequently, one objective of this paper is to specify a model where there is "churning." By this we mean that while most firms provide a level of quality consistent with their reputations, some firms are destroying a reputation for high quality, while others are establishing such a reputation. In our model, churning is a consequence of random cost shocks.

The second objective of this paper is to investigate whether churning undermines standard findings in the literature regarding implementation of a minimum quality standard (MQS). While this policy will not totally prevent cheating, it will lessen the magnitude of the disutility suffered by the victims, and potentially may discourage some firms from engaging in cheating. The traditional literature finds that raising the MQS reduces the equilibrium price of products whose quality is above the MQS. We find that this is not necessarily the case when there is a cost shock driven churning of firms.

\section{LITERATURE REVIEW}

The seminal works by Klein and Leffler (1981) and Shapiro (1983) developed models of competitive vertical differentiation in product quality. ${ }^{1}$ The authors describe a process by which some firms supply low quality while others choose to

\footnotetext{
${ }^{1}$ There is also a stream of literature in the early 1980 s that dealt with decisions by monopolists to create, and possibly milk, a reputation for quality (see the review in Tirole, 1988). Shaked and Sutton (1982) initiated a large literature on vertical differentiation under oligopolistic competition. Ronnen (1991) analyzed the effect on duopolists' quality choices from the imposition of a minimum quality standard. A dynamic version of Ronnen's paper is presented in the recent paper by Napel and Oldehaver (2011). Orosel and Zauner (2011) consider a game theoretic vertical differentiation model with assumptions about consumer behavior that are similar to our model, but without any cheating.
} 
invest to establish a reputation for high quality. Firms establishing a reputation incur an initial loss because they have to price consistent with low quality until consumers recognize, by consumption, that a high quality product is being offered. Consumers are then willing to pay a higher price for the firm's product. Firms that have established a reputation for high quality earn a price premium over cost that is just sufficient to repay over time their initial investment. In theory, these models allow for firms to milk a reputation by cheating. Cheaters could earn a profit until consumers become aware that they have been exploited. However, cheaters have to forgo the future price premiums associated with a high quality reputation. While the models set up a formal structure to analyze reputation formation and destruction, competitive equilibrium in these models is such that no firm has any incentive to actually cheat.

Shapiro devotes a considerable portion of his paper to considering the setting of an optimal MQS. Not surprisingly, he finds that raising the MQS reduces the price of high quality products. This is because the MQS raises the equilibrium price of low quality products, and reduces the initial loss incurred by firms in establishing a reputation for high quality. As a result, the price premium charged for high quality products will fall in competitive equilibrium. An optimal MQS is obtained when the marginal gains to the consumers of firms with a high quality reputation is equated with the marginal loses to the consumers of firms without such a reputation.

Moreover, in Shapiro's model, it is always desirable to intervene in the market to establish an MQS provided that there are zero enforcement costs. The reason is that an incremental increase in the MQS from the minimum feasible level of quality will force only marginal consumers of firms without a reputation for high quality out of the market, and these consumers are indifferent between consuming and not consuming. In contrast, all the other consumers, who patronize firms with a reputation for higher level(s) of quality, are unambiguously better off as price declines.

In the following decades, authors have proposed models to introduce the possibility of cheating in equilibrium. Gale and Rosenthal (1994) assume that established high quality firms are randomly dealt "death notices." The death notice takes the form of a warning that the firm will "die" in a specified (variable) number of time periods. ${ }^{2}$ Firms are aware of the probability of receiving a death notice and the distribution of the time from the warning to the actual death, and take this into account in setting price. Therefore, a firm drawing a particularly

\footnotetext{
${ }^{2}$ Gale and Rosenthal motivate their paper by reference to the possibility that an exogenous cost shock, such as a rise in property rents, might be the cause of a death notice. However, their story and modeling best describes shocks to the time preferences of a firm's owner (caused, say, by a change in her personal health or circumstances) rather than something that is inherent to the demand function or the production process.
} 
short duration from warning to death will be tempted to cheat. While this device does introduce the desired random cheating, it is not suitable for analyzing the comparative statics of altering an MQS because there is no formal link between the level of low quality and the probability of high quality firms receiving death notices.

An alternative mechanism for cheating derives from the possibility that a business with an established reputation for high quality might be sold to new owners. Methodologically, the origin for this line of the literature is Fudenberg and Levine (1992) who cast the maintenance or destruction of an existing reputation in a game theoretic way. Tadelis (1999) and Mailath and Samuelson (2001) describe models in which there are two types of firms: "inept" firms who can only produce low quality products and "competent" firms who can produce either low or high quality products. The papers deal with the possibility that inept firms may purchase an existing business with a good name or reputation for quality, and hence will cheat on that reputation because the transfer of ownership is only imperfectly observed by consumers.

Another plausible explanation for cheating would come from firm-specific shocks to demand and/or cost. Shocks to the demand system are problematic. There is a stream of the product quality literature where firm output is variable (such as Rogerson, 1983, and Allen, 1984), but the traditional competitive models and the present model constrain all operating firms to produce exactly the same amount of output in each time period. If the model structure was relaxed to permit idiosyncratic firm-specific demand shocks, such as might occur if firms were located along a tightly packed Hotelling-style line, it is possible that cheating might occur. However, such a story is not very appealing in that a temporary increase in demand rather than a decline will cause cheating, as the best time to cheat is when demand is highest. This is rather counterintuitive in that one would normally associate cheating with firms going through "bad" rather than "good" times. Our paper motivates cheating by investigating shocks to the cost function.

\section{MODEL OVERVIEW}

There are two discrete levels of product quality: low quality, $q_{L}$, and high quality, $q_{H}$. There is some minimum feasible level of quality, $q_{\min }$. This is defined by technological considerations, legal reasons (such as a finding of liability due to negligence), or because below a given level of quality it is certain that consumers can recognize that the product is shoddy. In the absence of an MQS, $q_{L}=q_{\min }$. The quality offered by a firm can only be determined by consumption. However, 
at the end of each period, after consumption has occurred, the quality offered by all firms becomes common knowledge. ${ }^{3}$

There are many heterogeneous consumers, each of which wishes to purchase at most one unit each time period. Consumers' preferences are characterized by a measure of the individual's intensity of preference for the product itself, denoted by $v \in[\underline{v}, \bar{v}]$, and intensity of preference for quality, denoted by $\theta \in[\underline{\theta}, \bar{\theta}]$. We assume that these variables are independently distributed across consumers according to the functions $F(v)$ and $K(\theta)$.

There are numerous profit-maximizing firms in the marketplace, with each producing at most one unit per time period. There are no barriers to entry or exit. Consequently, in equilibrium, expected long-run profits are driven to zero. Any firm can produce either high or low quality in a given time period. However, costs have two components, a set up cost and a production cost, both of which are incurred each period. Firms paying a set up cost consistent with high quality have the option of producing either high or low quality, whereas those paying a set up cost consistent with producing low quality only have the option of producing low quality.

A time line for each period is shown in Figure 1. Items shown above the line are known and observed by consumers, whereas those below the line are private information to the individual firms. At the beginning of the period consumers know the quality produced by each firm in the previous period. Firms will therefore fall into two groups. The first group consists of firms who have established a reputation for high quality by producing high quality in the previous period. The second group consists of a mix of firms who produced low quality in the previous period and new entrant firms. We will refer to this group as firms "without a reputation for high quality." Consumers are aware of the prices charged by these two groups of firms, which we will denote by $P_{H}$ and $P_{L}$ respectively. (Technically, these are prices charged by firms with and without a reputation for high quality, rather than the prices of high quality and low quality products, but we utilize the $\mathrm{H}$ and $\mathrm{L}$ subscripts for clarity of exposition.) These prices will be endogenously determined in our model based on a free-entry stationary equilibrium.

Firms initially decide whether to participate in the market. If they do, they pay a sunk set-up cost of $(1-\gamma) C(q)$, where $0<\gamma<1$, and $q \in\left\{q_{L}, q_{H}\right\} . \quad \gamma$ is exogenously determined by the technology of the industry and is invariant with $q$. One could think of this cost as the lease of equipment and/or the recurrent cost of

\footnotetext{
${ }^{3}$ Because each firm's quality becomes common knowledge at the end of each period, we do not require repeat purchase by a consumer from a single firm. Therefore, unlike Gale and Rosenthal (and also unlike other models of reputation such as that of Hörner, 2002), we do not need to specify a consumer search model.
} 
staff training. While we use the term "sunk" to describe this cost, this is not a "once only" expense as it has to be paid again at the start of every period. The other portion of the costs, $\gamma \alpha C(q)$, is subject to a random cost shock denoted by $\alpha$, where $\alpha \in\left[\alpha_{L}, \alpha_{H}\right]$, has a normalized mean of unity, and has density and distribution functions denoted by $g(\alpha)$ and $G(\alpha)$, respectively. ${ }^{4}$ The cost shock drawing occurs each time period after the sunk set up cost has been paid, and the realizations are independent of each other. Based on the magnitude of the shock, a firm who has paid for the option of producing either high or low quality then decides on the actual quality that it will produce. It has the option of continuing to produce the same level of quality that it did in the previous period, cheat on its reputation for high quality, or try to establish a reputation for high quality. Both these firms, and the firms who paid for the option of only being able to produce low quality, could decide not to produce if the cost shock is extremely high. All of these decisions by firms are hidden from consumers.

\section{FIGURE 1: Time Line per Period}

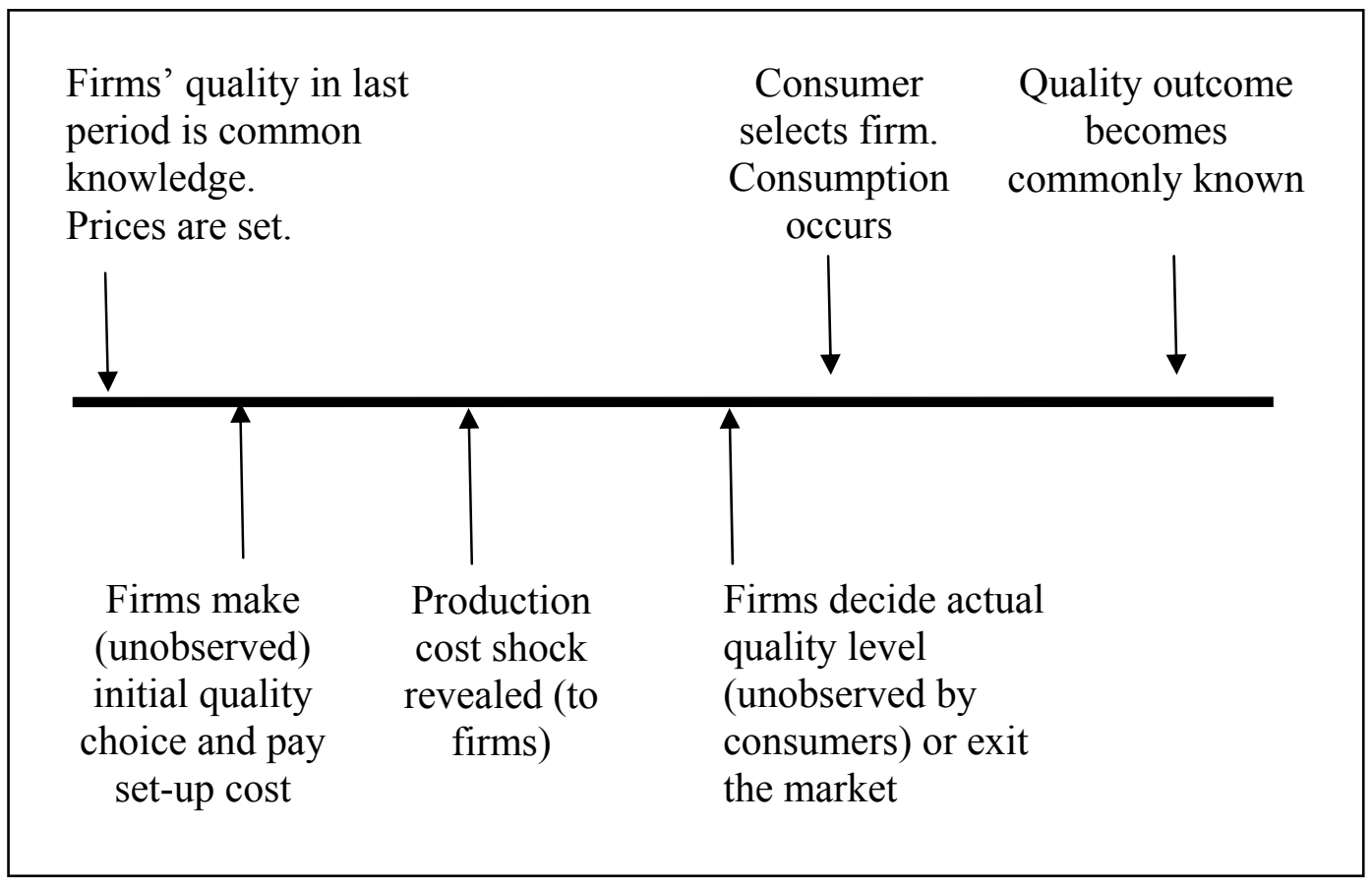

\footnotetext{
${ }^{4}$ The two basic requirements of our model are that costs have a sunk component, and the cost shock has a greater absolute effect on high quality costs than it does on low quality costs. In the absence of sunk costs, only firms drawing the minimum cost parameter will be tempted to establish a reputation for high quality. In the next period it is highly unlikely that they will draw the minimum again, so they will cheat immediately or shut down.
} 
Consumers then decide about which firm to patronize. Consumers know that a proportion of the group of firms with a reputation for high quality will actually be cheaters and will deliver low quality. We will define a stationary equilibrium in which the proportion of cheaters is endogenously determined. This proportion will be known by consumers, but they do not know the identity of the individual cheaters. Similarly, among the group of firms without a reputation for high quality, there will be a known proportion of unidentified firms that are in the process of establishing a reputation and will deliver a "pleasant surprise" by providing high quality at a price consistent with low quality. Consequently the expected quality provided by firms with a reputation for high quality will be somewhat less than $q_{H}$, and that offered by those without a reputation for high quality will be somewhat more than $q_{L}$. A practical example of such a market is the restaurant industry. Individual diners patronize many places over the course of a year. Diners are aware that a proportion of the restaurants with a reputation for high quality are actually on the decline and will disappoint, and that among the restaurants that lack such a reputation there are "hidden gems" that will be the recognized high quality establishments of tomorrow.

Rational consumers compare prices and expected quality levels and decide on whether firms with or without a reputation for high quality best match their preferences. Our stationary equilibrium is such that the quality expectations of consumers are fulfilled. Consumers then randomly patronize firms that have a reputation for the quality that they prefer. Some consumers might find that the prices and expected qualities on offer are such that they decide not to participate in the market. Consumption then occurs. Quality is revealed and becomes common knowledge. The cycle then repeats itself.

\section{MODEL DETAILS}

This section gives details on the equilibrium decision making of firms and consumers. The model endogenously determines prices, the proportion of firms among those with a reputation for high quality who are cheaters, and the proportion of firms without a reputation for high quality who confer a pleasant surprise because they are establishing a reputation.

Initially we will look at the equilibrium conditions for firms. To assist in the description, a decision tree is shown in Figure 2. Firms without a reputation for high quality are shown in the panel on the left, and those with an existing reputation for high quality are shown in the panel on the right. 

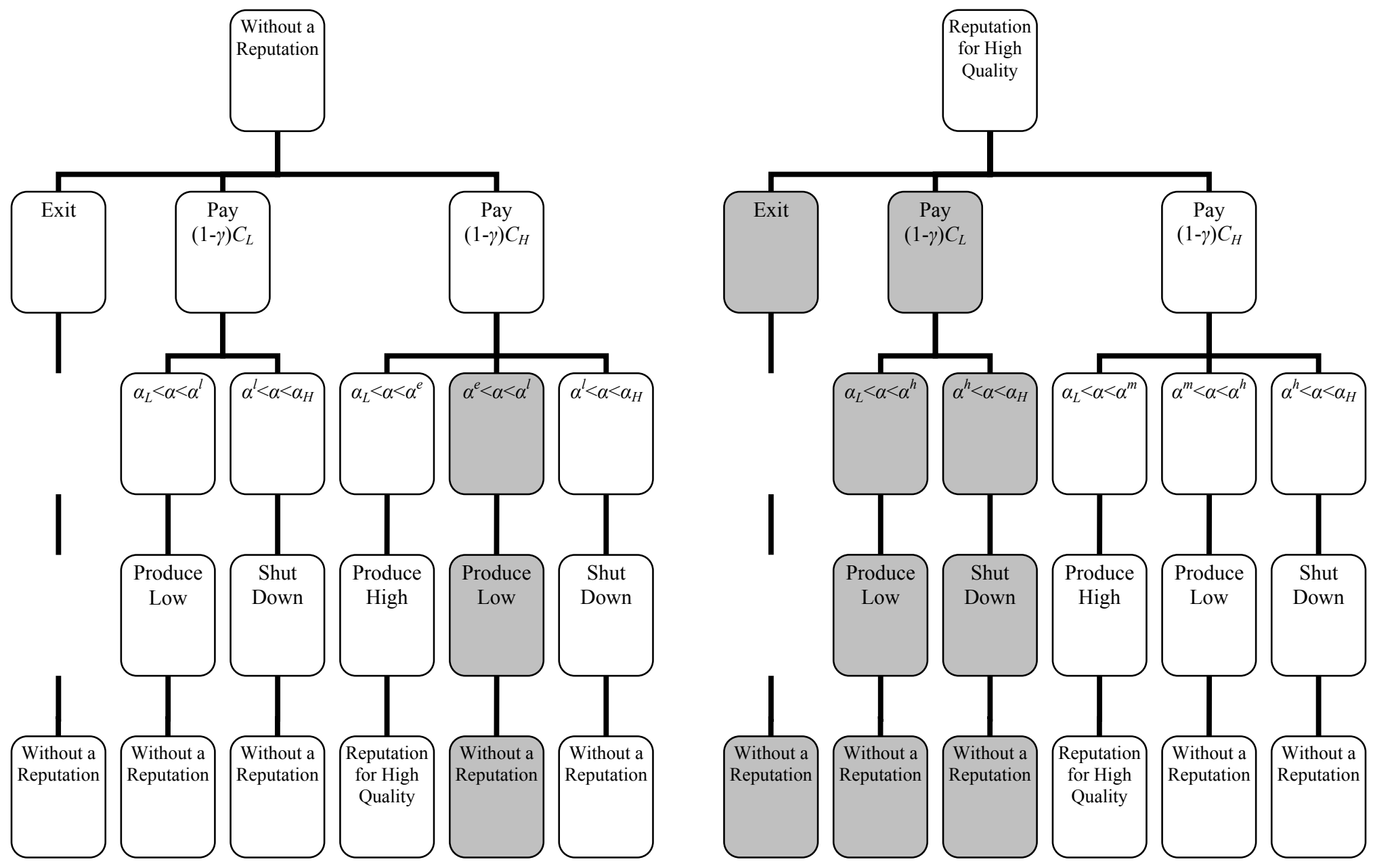

FIGURE 2: Sequence of Firm Choices and Reputation at Beginning and End of a Period. 
The figure shows the alternatives available to these firms depending on whether they pay the sunk set up cost associated with low or high quality, and the subsequent outcome of their draw of $\alpha$. Finally, in the bottom row, we show the reputation that the firm will hold as it enters the next time period. Branches of the tree that are shaded represent options that we will discover are not selected by firms.

We make one notational simplification. We will abbreviate $C\left(q_{\min }\right)$ to $C_{\min }, C\left(q_{L}\right)$ to $C_{L}$ and $C\left(q_{H}\right)$ to $C_{H}$. Because at this point, we have yet to introduce an MQS, $C_{L}=C_{m i n}$.

\subsection{Firms Without a REPUTATION FOR High QUALITY THAT INTEND TO Produce Low Quality}

At the beginning of a period, a firm that either produced low quality in the previous period or is a new entrant has three alternatives: (1) it can stay out of the market; (2) it pays a sunk cost intending to produce a low quality product, or (3) it pays a sunk cost intending to establish a reputation for high quality. We include option (1) which generates zero profits because our free-entry condition means that there are also zero expected profits from entering the market.

This section focuses on option (2) which is represented by the middle branch of the left-hand panel of Figure 2. A firm pays its sunk cost of $(1-\gamma) C_{L}$, and receives a draw of $\alpha$. It is possible that it receives a sufficiently unfavorable cost draw that it is more profitable to shut down for that period (and forfeit its sunk costs). We will denote the cost shock that leaves the firm just indifferent as $\alpha$. Firms obtaining a more favorable cost shock will produce, and have an average cost shock defined by the following lower partial moment:

$$
\underline{\alpha}\left(\alpha^{l}\right) \equiv \frac{\int_{\alpha_{L}}^{\alpha^{l}} \alpha g(\alpha) d \alpha}{\int_{\alpha_{L}}^{\alpha^{l}} g(\alpha) d \alpha}=\frac{\int_{\alpha_{L}}^{\alpha^{l}} \alpha g(\alpha) d \alpha}{G\left(\alpha^{l}\right)}
$$

The expected profit in the period, which is driven to zero by free-entry, is given by:

$$
G\left(\alpha^{l}\right)\left\lfloor P_{L}-\underline{\alpha}\left(\alpha^{l}\right) \gamma C_{L}\right\rfloor-(1-\gamma) C_{L}=0
$$

This equation only covers the payoffs in the current period, as a low quality firm will repeat this calculation at the start of each period. One will note that price is set in such a way that the firm expects to just cover both the sunk set-up cost and the production cost. If price was forced down to cover just the production cost 
then firms will earn negative profits, and no firms would elect to participate in the market in future periods.

Further insight can be obtained because we can express $P_{L}$ in terms of $\alpha^{l}$. Recognizing that the shut down decision is made after the sunk cost has been paid, the payoffs for a firm at the point of indifference between producing and shutting down are:

$$
P_{L}-\alpha^{l} \gamma C_{L}=0 \Rightarrow P_{L}=\alpha^{l} \gamma C_{L}
$$

Substituting equation (3) into equation (2) and collecting terms produces a condition characterizing the firm's shutdown threshold $\alpha$ :

$$
Z\left(\alpha^{l}\right) \equiv G\left(\alpha^{l}\right)\left[\alpha^{l}-\underline{\alpha}\left(\alpha^{l}\right)\right]=\frac{1-\gamma}{\gamma} .
$$

For future reference, we note that $Z(\alpha)$ is convex and strictly increasing: i.e., $Z^{\prime}(\alpha)$ $=G(\alpha)>0$ and $Z^{\prime \prime}(\alpha)=g(\alpha) \geq 0$. Also, $Z\left(\alpha_{L}\right)=0$ and $Z\left(\alpha_{H}\right)=\alpha_{H}-1$. Thus equation (4) uniquely defines $\alpha_{L}<\alpha<\alpha_{H}$ as long as $\left(1 / \alpha_{H}\right)<\gamma<1$, and equation (3) permits determination of $P_{L}$.

\subsection{Firms Intending to Produce High Quality}

\subsubsection{Firms without a Reputation that wish to Establish a Reputation for High Quality}

Firms establishing reputations for high quality can be either new entrants to the industry or existing low quality firms who wish to move "up market." These firms are represented by the third branch in the left-hand panel of Figure 2. After each firm has paid its sunk cost of $(1-\gamma) C_{H}$, it receives a realization of $\alpha$. Depending on the value of this realization, the firm has three choices: (1) it decides to proceed and establish its reputation by producing a high quality product, (2) it obtains an unfavorable cost shock and decides it is more profitable to produce low quality, or (3) the cost shock is so unfavorable that the firm prefers to shut down rather than produce. Let us denote the critical value where the firm is indifferent between options (1) and (2) as $\alpha^{\mathscr{E}}$. The critical value where the firm is indifferent between options (2) and (3) will be $\alpha$, as the firm is making the same choice as the firm intending to produce low quality as described in the previous section.

The expected profit, which will be driven to zero by free entry, is given by:

$$
G\left(\alpha^{e}\right)\left[P_{L}-\underline{\alpha}\left(\alpha^{e}\right) \gamma C_{H}+\frac{V_{H}}{(1+r)}\right]+\int_{\alpha^{e}}^{\alpha^{l}}\left[P_{L}-\alpha \gamma C_{L}\right] g(\alpha) d \alpha-(1-\gamma) C_{H}=0
$$


$V_{H}$ denotes the net present value of entering the next period with an established reputation for high quality, and $r$ is the per-period interest rate. (Note that $V_{H}$ will be positive even when overall expected profit is zero because it represents the value of entering the next period with a reputation for high quality, and firms will need to just recoup the initial investment in establishing a reputation.) Further insight can be obtained because we know that at $\alpha^{e}$,

$$
P_{L}-\alpha^{e} \gamma C_{H}+\frac{V_{H}}{1+r}=P_{L}-\alpha^{e} \gamma C_{L}
$$

Upon rearrangement, we obtain a simple expression for the value of an established reputation for high quality:

$$
V_{H}=(1+r) \alpha^{e} \gamma\left[C_{H}-C_{L}\right]
$$

Substituting equations (3) and (7) into equation (5) yields the following expression:

$G\left(\alpha^{e}\right)\left[\alpha^{e}-\underline{\alpha}\left(\alpha^{e}\right)\right] C_{H}+C_{L}\left\{\alpha^{l} G\left(\alpha^{l}\right)-\alpha^{e} G\left(\alpha^{e}\right)-\int_{\alpha^{e}}^{\alpha^{l}} \alpha g(\alpha) d \alpha\right\}=\frac{(1-\gamma) C_{H}}{\gamma}$.

Upon further rearrangement, we obtain:

$C_{H} G\left(\alpha^{e}\right)\left[\alpha^{e}-\underline{\alpha}\left(\alpha^{e}\right)\right]+C_{L}\left\{G\left(\alpha^{l}\right)\left[\alpha^{l}-\underline{\alpha}\left(\alpha^{l}\right)\right]-G\left(\alpha^{e}\right)\left[\alpha^{e}-\underline{\alpha}\left(\alpha^{e}\right)\right]\right\}=\frac{(1-\gamma) C_{H}}{\gamma}$

Using the definition of $Z$, this becomes:

$$
C_{H} Z\left(\alpha^{e}\right)-C_{L} Z\left(\alpha^{e}\right)+C_{L} Z\left(\alpha^{l}\right)=\frac{(1-\gamma) C_{H}}{\gamma}
$$

Rearranging:

$$
\left(C_{H}-C_{L}\right) Z\left(\alpha^{e}\right)=\frac{(1-\gamma) C_{H}}{\gamma}-C_{L} Z\left(\alpha^{l}\right)
$$


In equilibrium, equation (4) tells us that the right hand side can be expressed as $\left(C_{H^{-}} C_{L}\right) Z\left(\alpha^{l}\right)$. This establishes that in equilibrium $Z\left(\alpha^{\circ}\right)=Z(\alpha)$. Since $Z$ is strictly increasing, it also establishes that $\alpha^{\mathscr{f}}$ also equals $\alpha$. We will denote this value as $\alpha^{*}=\alpha^{\mathcal{L}}=\alpha$.

Because $\alpha^{q}=\alpha$, it turns out that firms intending to establish a reputation have only two relevant outcomes from the cost shock draw. If $\alpha<\alpha^{*}$ they go ahead and establish a reputation, and if $\alpha>\alpha^{*}$ they shut down. The free-entry condition, equation (5), simplifies to:

$$
G\left(\alpha^{*}\right)\left[P_{L}-\underline{\alpha}\left(\alpha^{*}\right) \gamma C_{H}+\frac{V_{H}}{(1+r)}\right]-(1-\gamma) C_{H}=0 .
$$

\subsubsection{FiRMS WITH AN EXISTING REPUTATION FOR HIGH QUALITY}

These firms are shown in the right-hand panel of Figure 2. We have already established that obtaining a reputation for high quality is valuable, therefore no firm will choose to shut down without paying its sunk cost and earn zero profits both in this period and in the future (because it will have destroyed its reputation). In an appendix we will demonstrate that there is no positive incentive for the firm to preemptively cheat by paying a set-up cost of $(1-\gamma) C_{L}$. Therefore, only the right-hand branch is relevant to our discussion. Firms with a reputation for high quality will attempt to maintain that reputation by paying a sunk cost consistent with high quality. However, some will have a sufficiently unfavorable cost shock realization that they choose to cheat, and others will receive such an extreme cost shock that they decide to shut down.

We will denote the value of the cost shock at which an existing high quality firm is indifferent between cheating and maintaining its reputation as $\alpha^{n}$. This point is characterized by:

$$
P_{H}-\alpha^{m} \chi_{H}+\frac{V_{H}}{1+r}=P_{H}-\alpha^{m} \gamma_{L} .
$$

Comparing equation (9) with equation (6) indicates that the critical values of the cost shock for establishing and maintaining a reputation are the same. Hence, $\alpha^{n}$ $=\alpha^{\mathcal{e}}=\alpha=\alpha^{*}$. The critical value where firms are indifferent between cheating and shutting down will be denoted as $\alpha^{h}$, and will be defined when:

$$
P_{H}-\alpha^{h} \gamma C_{L}=0 \Rightarrow P_{H}=\alpha^{h} \gamma C_{L} .
$$


We can now write down a more tangible (recursive) definition of $V_{H}$, the expected discounted present value of entering any period with a high quality reputation:

$$
\begin{aligned}
V_{H}=G\left(\alpha^{*}\right)\left[\left[P_{H}-\underline{\alpha}\left(\alpha^{*}\right) C_{H}\right]+\frac{V_{H}}{(1+r)}\right] \\
+\int_{\alpha^{*}}^{\alpha^{h}}\left[P_{H}-\alpha \gamma C_{L}\right] g(\alpha) d \alpha-(1-\gamma) C_{H}
\end{aligned}
$$

The first term on the right-hand side is the probability that the firm will choose not to cheat times the expected gross profits resulting from producing and selling a high quality product this period plus the (discounted) value of beginning the next period with its high quality reputation intact. The integral is the expected gross profit contribution when the cost draw is high enough to induce the firm to cheat, but not high enough to cause it to shut down. If $\alpha>\alpha^{h}$, the firm shuts down. The last term is the sunk cost that the firm has to pay regardless of the outcome.

The shut down point, $\alpha^{h}$, can be determined from equation (11) by initially substituting for $P_{H}$ using equation (10). We then impose the free entry condition in equation (8). Equation (8) says that the expected first period loss in establishing a reputation for high quality just equals the net present value of the price premium from entering the next period with a reputation. Substituting the free entry definition of $V_{H}$ from equation (7) into equation (11), then utilizing the free-entry definition of $Z\left(\alpha^{*}\right)$ from equation (4), and rearranging yields:

$$
Z\left(\alpha^{h}\right)=Z\left(\alpha^{*}\right)+\frac{(1+r) \alpha^{*}\left[C_{H}-C_{L}\right]}{C_{L}}>Z\left(\alpha^{*}\right) .
$$

Since $Z$ is strictly increasing, this equation implicitly defines a unique $\alpha^{h}>\alpha^{*}$. Hence we also obtain the price of high quality using the relationship in equation (10).

\subsection{INTERIOR VERSUS CORNER SOLUTIONS}

The equilibrium conditions just described are for interior values of $\alpha^{*}$ and $\alpha^{h}$. In considering corner solutions, we will initially consider the case where $\alpha^{*}$ is 
interior but $\alpha^{h}=\alpha_{H}{ }^{5}$ We do this because equation (12) tells us that $\alpha^{h}>\alpha^{*}$. Equation (11) now becomes:

$$
\begin{aligned}
V_{H}=G\left(\alpha^{*}\right)\left[\left[P_{H}-\underline{\alpha}\left(\alpha^{*}\right) C_{H}\right]+\frac{V_{H}}{(1+r)}\right] \\
+\int_{\alpha^{*}}^{\alpha_{H}}\left[P_{H}-\alpha \gamma C_{L}\right] g(\alpha) d \alpha-(1-\gamma) C_{H}
\end{aligned}
$$

Substituting using equations (1), (4) and (7) and rearranging yields a simpler expression for the price charged by firms with a reputation for high quality:

$$
P_{H}=C_{L}+(1+r) \alpha^{*} \gamma\left(C_{H}-C_{L}\right) .
$$

Equation (4) indicates that when $\gamma$, the proportion of total cost that is not sunk when measured at the mean value of the cost shock, is less than or equal to $1 / \alpha_{H}$ there is a corner solution with $\alpha^{*}$, and by definition $\alpha^{h}$, equal to $\alpha_{H}$. Now all firms decide to produce, and there is no cheating. ${ }^{6}$ When $\alpha^{l}\left(=\alpha^{*}\right)=\alpha_{H}$, and $\gamma=$ $1 / \alpha_{H}$, equation (3) simplifies to:

$$
P_{L}=C_{L}
$$

Setting $\alpha^{*}$ to $\alpha_{H}$ in equation (8), and rearranging, produces the expression:

$$
C_{H}-P_{L}=V_{H} /(1+r) \text {. }
$$

${ }^{5}$ By definition, when $\alpha^{h}=\alpha_{H}, Z\left(\alpha^{h}\right)=\alpha^{h}-1$. Therefore, equation (12) tells us that $\alpha^{h}$ will be interior when:

$$
Z\left(\alpha^{*}\right)+\frac{(1+r) \alpha^{*}\left[C_{H}-C_{L}\right]}{C_{L}}<\alpha_{H}-1 .
$$

Substituting from equation (4) for $Z\left(\alpha^{*}\right)$ and rearranging produces the condition for an interior $\alpha^{h}$ :

$$
\frac{1}{\gamma}+\frac{(1+r) \alpha^{*}\left[C_{H}-C_{L}\right]}{C_{L}}<\alpha_{H} .
$$

${ }^{6}$ Equation (4) shows that $\alpha^{l}=\alpha_{H}$ when $\gamma=1 / \alpha_{H}$. The same is true for $\alpha^{e}$ because $Z\left(\alpha^{e}\right)=Z\left(\alpha^{l}\right)$, and for $\alpha^{m}$ because equations (6) and (9) are similar. 
The discounted value of entering the subsequent period with a reputation for high quality exactly compensates for the loss incurred in the initial period in establishing the reputation. A similar interpretation can be derived from setting $\alpha^{*}$ to $\alpha_{H}$, and $\gamma$ to $1 / \alpha_{H}$ in equation (14), to produce:

$$
P_{H}=C_{H}+r\left[C_{H}-C_{L}\right]
$$

The price charged by firms with a reputation for high quality is composed of the production costs and a premium to recoup, over time, the initial investment in establishing a reputation. Equations (15) and (16) are identical to the price equations in Shapiro's model. Therefore random cost variation does not necessarily invalidate Shapiro's findings, provided that the variation is small. For a given value of $\gamma$, where $0<\gamma<1$, the value of the maximum cost shock has to be at least $1 / \gamma$ before it is worthwhile for firms to cheat. Interestingly, only the absolute value of $\alpha_{H}$ is crucial to this determination, and not any other parameters of the $g(\alpha)$ distribution.

\subsection{CONSUMERS}

Consumers are fully informed about prices, the reputation for quality of each firm, and the proportion of cheater firms among those with a reputation for high quality that produce rather than shut down. This proportion is given by:

$$
\frac{G\left(\alpha^{h}\right)-G\left(\alpha^{*}\right)}{G\left(\alpha^{h}\right)}=1-\frac{G\left(\alpha^{*}\right)}{G\left(\alpha^{h}\right)} .
$$

Consumers are also aware of the proportion of reputation establishing firms in the population of firms that do not have a reputation, which we will denote by $\mu$.

In our steady state equilibrium the number of firms successfully establishing a high quality reputation in any period must exactly equal the number of existing high quality firms destroying their reputation by cheating or shutting down. Because we have constrained firms and consumers to produce or consume a maximum of one unit per period (i.e., active consumers are equal to active firms), and defining the number of consumers patronizing firms with and without a reputation for high quality as $X_{H}$ and $X_{L}$, respectively, the following identity holds:

$$
\mu X_{L}=\frac{\left[1-G\left(\alpha^{*}\right)\right]}{G\left(\alpha^{h}\right)} X_{H} .
$$


Note that $\mu$ is defined relative to the number of firms that are actually trading without a reputation for high quality. For an interior solution, there will be additional firms that receive unfavorable cost shocks greater than $\alpha^{*}$ that shut down prior to producing.

The nature of the consumers' choice and the determination of $X_{H}$ and $X_{L}$ can be illustrated using a convenient separable, quasi-linear form for a consumer's net benefit (surplus) from consuming the product:

$$
B(p, q, v, \theta)=v-p+\theta q
$$

By construction, the surplus associated with non consumption is zero. Consumers will be indifferent when $E_{H}$, the net expected utility of purchasing from a firm with a reputation for high quality, exactly equals $E_{L}$, the net expected utility of purchasing from a firm without a reputation for high quality:

$$
\begin{aligned}
E_{H}=v-P_{H}+\theta & \left\{\frac{G\left(\alpha^{*}\right)}{G\left(\alpha^{h}\right)} q_{H}+\left[1-\frac{G\left(\alpha^{*}\right)}{G\left(\alpha^{h}\right)}\right] q_{L}\right\} \\
& =v-P_{L}+\theta\left[(1-\mu) q_{L}+\mu q_{H}\right]=E_{L}
\end{aligned}
$$

This equation can be rearranged to solve for the critical value, $\theta_{L H}$, for which consumers are just indifferent:

$$
\theta_{L H}=\frac{P_{H}-P_{L}}{\left[\frac{G\left(\alpha^{*}\right)}{G\left(\alpha^{h}\right)}-\mu\right]\left(q_{H}-q_{L}\right)} .
$$

Consumers with values of $\theta$ greater than $\theta_{L H}$ prefer to purchase from firms with a reputation for high quality rather than patronize firms without such a reputation, regardless of their value of $v .^{7}$

Equating $E_{H}$ to zero and rearranging terms yields the following formula characterizing the values of $v$ and $\theta$ for which consumers are indifferent between purchasing from firms with a reputation for high quality products and not purchasing at all:

\footnotetext{
${ }^{7}$ It should be noted that to obtain an interesting equilibrium, the amount of cheating cannot be too excessive. To ensure that there is actually a market for firms with a reputation for high quality, we require that the average quality actually provided by firms with a reputation for high quality exceeds that of the firms without such a reputation.
} 


$$
v_{H 0}(\theta)=P_{H}-\theta\left\{\frac{G\left(\alpha^{*}\right)}{G\left(\alpha^{h}\right)} q_{H}+\left[1-\frac{G\left(\alpha^{*}\right)}{G\left(\alpha^{h}\right)}\right] q_{L}\right\} .
$$

For any given value of $\theta$, consumers with a $v$ greater than $v_{H 0}$ prefer to patronize firms with a reputation for high quality rather than make no purchase. Similarly, we can define:

$$
v_{L 0}(\theta)=P_{L}-\theta\left[(1-\mu) q_{L}+\mu q_{H}\right]
$$

For any given value of $\theta$, consumers with a $v$ greater than $v_{L 0}$ prefer to patronize firms without a reputation for high quality rather than make no purchase.

FIGURE 3: Consumer Choice between Not Consuming and Patronizing Firms with and without a Reputation for High Quality

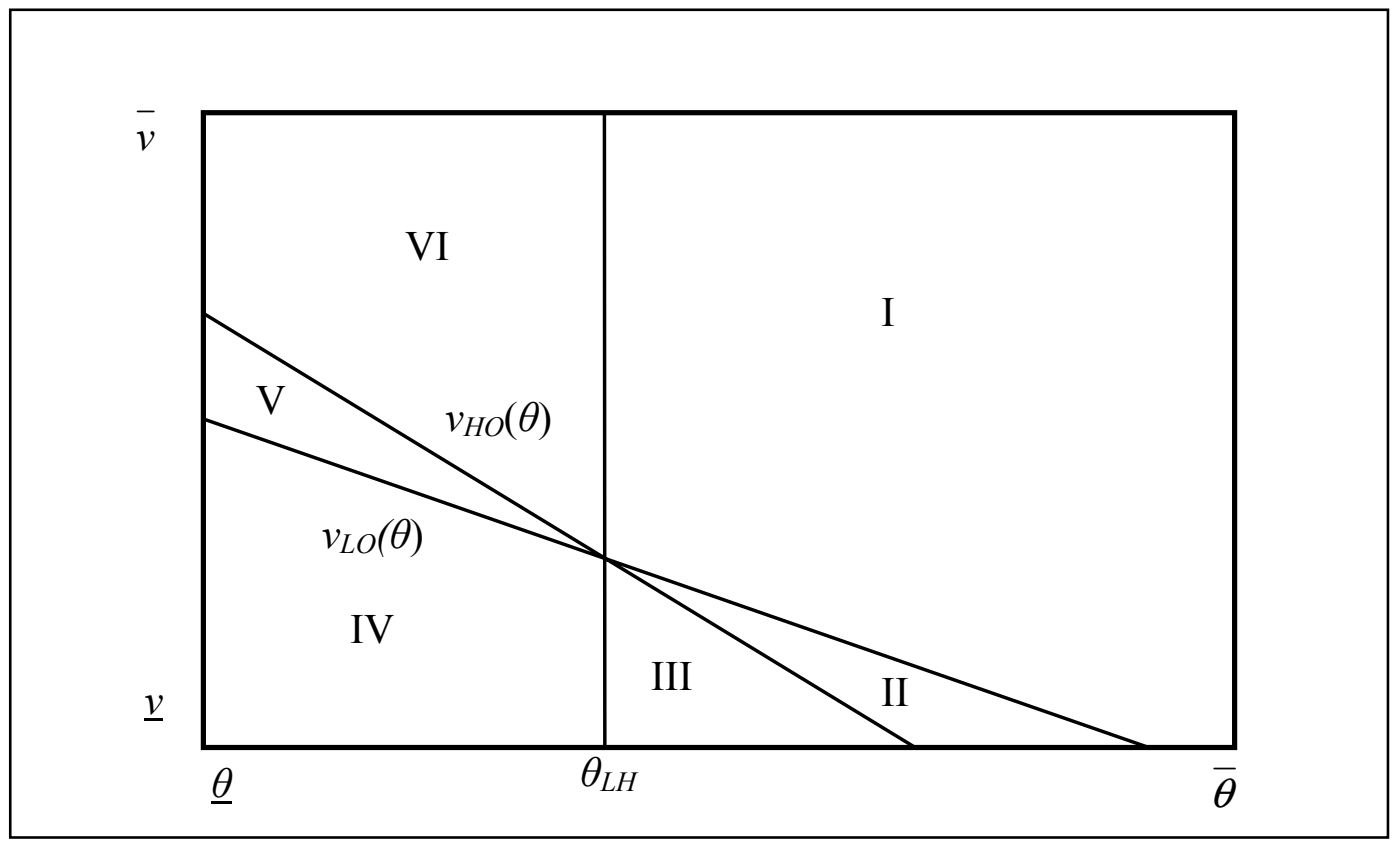

The total demand for firms without a reputation for high quality is given by:

$$
X_{L}=\int_{\underline{\theta}}^{\theta_{L H}}\left[\int_{v_{L 0}(\theta)}^{\bar{v}} f(v) d v\right] k(\theta) d \theta
$$


where $f(v)$ and $k(\theta)$ are the density functions associated with $F(v)$ and $K(\theta)$, respectively. Similarly, consumers desiring to patronizing firms with a reputation for high quality have a demand function given by:

$$
X_{H}=\int_{\theta_{L H}}^{\bar{\theta}}\left[\int_{v_{H 0}(\theta)}^{\bar{v}} f(v) d v\right] k(\theta) d \theta .
$$

Collectively equations (18) and (21)-(25) determine $\mu, X_{L}$ and $X_{H}$, the remaining endogenous variables in the model. The demand system is illustrated in Figure 3. Consumers whose $(v, \theta)$ values lie in regions I and II purchase from firms with a reputation for high quality. Consumers who lie in regions V and VI purchase from firms without a reputation for high quality. Those in regions III and IV do not purchase at all.

\subsection{FIRM NUMBERS AND DYNAMICS}

We are now able to fully represent the dynamics of firm reputation from period to period. A simplified version of Figure 2 is shown in Figure 4. The initial reputation of the firm at the start of a period is shown in the box on the left, and the ultimate production decisions are at the right. The number of firms associated with each outcome is indicated by $n_{1}$ through $n_{7}$.

\section{FIGURE 4: Summary of Firm Choices Each Period}

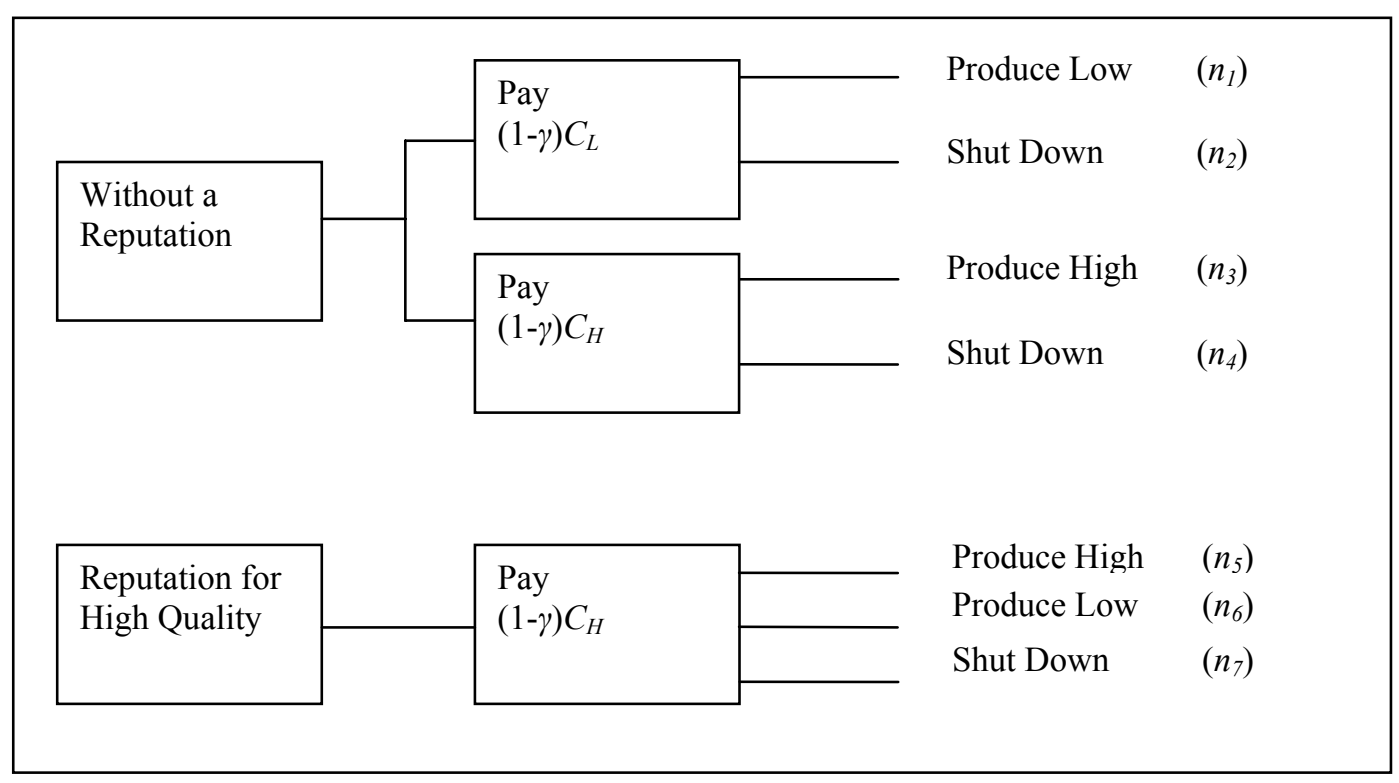


In equilibrium the following relationships will hold:

$$
\begin{array}{ll}
n_{1}+n_{3}=X_{L} & n_{5}+n_{6}=X_{H} \\
n_{1}=G\left(\alpha^{*}\right)\left(n_{1}+n_{2}\right) & n_{3}=G\left(\alpha^{*}\right)\left(n_{3}+n_{4}\right) \\
n_{5}=G\left(\alpha^{*}\right)\left(n_{5}+n_{6}+n_{7}\right) & n_{6}=\left[G\left(\alpha^{h}\right)-G\left(\alpha^{*}\right)\right]\left(n_{5}+n_{6}+n_{7}\right) \\
\mu=n_{3} /\left(n_{1}+n_{3}\right) & n_{3}=n_{6}+n_{7}
\end{array}
$$

We note that because some firms $\left(n_{2}+n_{4}+n_{7}\right)$ decide to shut down and not produce, there are less firms operating at the end of a period than at the beginning. As we move into the next period, the number of firms with a reputation for high quality is replenished by the $n_{3}$ firms who successfully established a reputation in the previous period. But among the group of firms without a reputation there has been a net loss of $n_{2}+n_{3}+n_{4}-n_{6}$ firms. Consequently, even in stable equilibrium, there will be firms entering the market at the start of each period. These can be either genuinely new firms, or firms who have shut down previously and re-enter the market without a reputation for high quality.

\section{IMPOSING A MINIMUM QUALITY STANDARD}

We now turn to an analysis of the setting, and altering, of a minimum quality standard. Previously we had assumed that $q_{L}=q_{\min }$. Now, the imposition of the standard will define $q_{L}$ such that $q_{H} \geq q_{L}>q_{\text {min }}$. We will assume that the government can perfectly enforce the MQS, and the promulgation and enforcement of the MQS is costless. The MQS is manifested in our model through the variable $C_{L}$. Consequently, the effect of a small change in the MQS on the equilibrium values of the endogenous variables can be analyzed by performing a comparative statics analysis with respect to $C_{L}$.

\subsection{THE EFFECT ON $\alpha^{*}$ AND $\alpha^{h}$}

Equation (4) reveals that $\alpha^{*}$ does not depend upon $C_{L}$. While the MQS will not affect $\alpha^{*}$, the effect on $\alpha^{h}$ is complex. If $\alpha^{h}$ equals $\alpha_{H}$ when $C_{L}=C_{\text {min }}$, footnote 5 indicates that the MQS has to be raised above a certain level before $\alpha^{h}$ becomes interior. If $\alpha^{h}$ is interior at $C_{L}=C_{\text {min }}$, or when it becomes interior, equation (12) reveals that $Z\left(\alpha^{h}\right)$ and hence $\alpha^{h}$ will fall as $C_{L}$ increases. The intuition is that as $C_{L}$ increases the one-time cost reduction benefit to the firm from cheating diminishes, and it is more likely that the firm will choose to shut down instead. In 
the limit, if the MQS was raised all the way to $q_{H}$, then $\alpha^{h}$ will become equal to $\alpha^{*}$.

\subsection{The EfFect ON Prices}

\subsubsection{Price Charged by Firms without a Reputation for High Quality}

Because equation (4) tell us that $\alpha^{*}$ does not depend upon $C_{L}$, we can tell from equation (3) that $\partial P_{L} / \partial C_{L}>0$. A higher MQS will increase the equilibrium price for firms without a reputation for high quality.

\subsubsection{Price Charged by Firms with a Reputation for High Quality when $\alpha^{\text {h }}$ is INTERIOR}

Differentiating equation (10) with respect to $C_{L}$, we observe that the price of high quality will increase if:

$$
\left|\frac{\partial \alpha^{h}}{\partial C_{L}}\right|<\frac{\alpha^{h}}{C_{L}} .
$$

Equation (26) tells us that an increase in the MQS will tend to increase price when the product is relatively inexpensive $\left(C_{L}\right.$ is small) and/or when $\alpha^{h}$ is large. The latter is more likely when the cost shocks have a large range rather than being tightly distributed around the mean.

Additional insights into the countervailing influences on $P_{H}$ can be obtained from making $V_{H}$ the subject of equation (11) and substituting into equation (8) to produce:

$$
\begin{aligned}
& G\left(\alpha^{*}\right)\left\lfloor P_{L}-\underline{\alpha}\left(\alpha^{*}\right) \gamma C_{H}\right\rfloor-(1-\gamma) C_{H}
\end{aligned}
$$

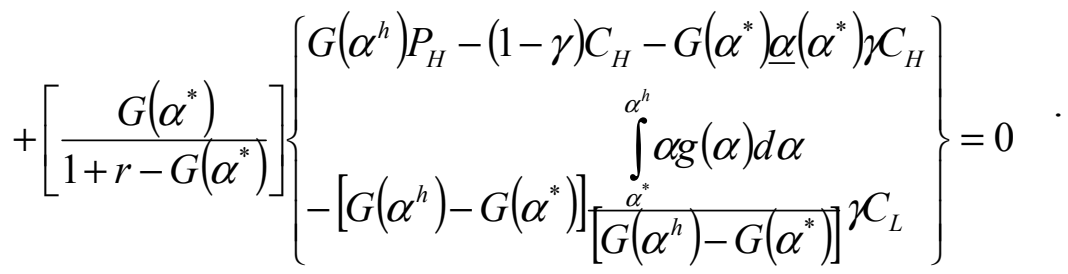

Upon rearrangement, we obtain: 


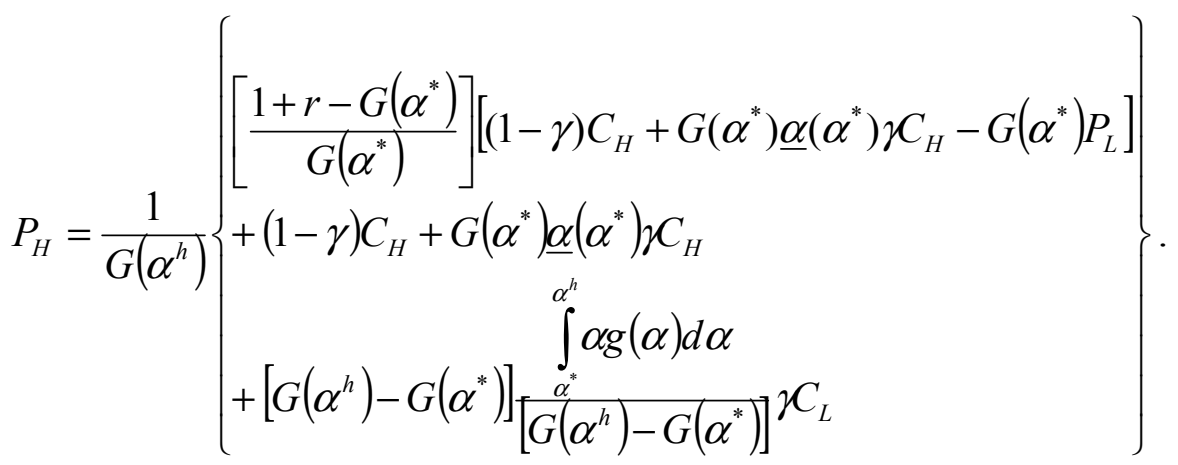

Increasing the MQS affects equation (28) in three ways. The first effect concerns the term outside the parentheses. This term represents a price premium to compensate for the probability that the firm may shut down and earn no revenue. As the MQS increases, the proportion of firms that shut down increases $\left(\partial \alpha^{h} / \partial C_{L}<0\right)$, and the price will increase to compensate for the increased chance that the firms may earn no revenue. The second effect concerns the first term inside the curly parentheses. This term decreases as the MQS increases, because it represents the recouping over time of the initial investment to establish a reputation. The higher price charged by firms without a reputation as the MQS increases leads to a smaller initial investment to establish a reputation.

The final effect concerns the remaining terms in the curly parentheses. These terms represent the average cost of production of the firms that entered the period with a reputation for high quality. Some of these firms actually produce at high quality, some cheat, and others shut down and incur no production costs. The MQS only affects the last of these terms, which represents the weighted average cost of those firms who cheat. The MQS has three distinct effects on this term. It will increase the term directly through the effect on $C_{L}$. However, it will reduce the middle part of the term which represents the mean cost shock between $\alpha^{*}$ and $\alpha^{h}$, because increasing the MQS moves $\alpha^{h}$ closer to $\alpha^{*}$. Increasing the MQS also reduces the proportion of firms that cheat, and implicitly represents the fact that a larger proportion of the firms will now shut down and do not incur any production costs.

\subsubsection{Price Charged by Firms with a Reputation for High Quality when $\alpha^{\mathrm{h}}=\alpha_{\mathrm{H}}$}

It is impossible to determine the sign of the relationship between the MQS and $P_{H}$ even in the case where a change in the MQS leaves $\alpha^{h}$ unchanged at $\alpha_{H}$. Differentiating equation (14) with respect to $C_{L}$ gives: 


$$
\frac{\partial P_{H}}{\partial C_{L}}=1-(1+r) \alpha^{*} \gamma
$$

The price will increase with a rise in the MQS when variable production costs are a small proportion of total cost, the discount rate is low, and the magnitude of the cost shocks is small and/or there is a lot of cheating ( $\alpha^{*}$ will tend to be small).

To obtain additional insights, we can simplify equation (28) when $\alpha^{h}=$ $\alpha_{H}$ :

$$
\begin{aligned}
P_{H}= & {\left[\frac{1+r-G\left(\alpha^{*}\right)}{G\left(\alpha^{*}\right)}\right]\left[(1-\gamma) C_{H}+G\left(\alpha^{*}\right) \underline{\alpha}\left(\alpha^{*}\right) \gamma C_{H}-G\left(\alpha^{*}\right) P_{L}\right] . } \\
& +(1-\gamma) C_{H}+G\left(\alpha^{*}\right) \underline{\alpha}\left(\alpha^{*}\right) \gamma C_{H}+\left[1-G\left(\alpha^{*}\right)\right] \bar{\alpha}\left(\alpha^{*}\right) \gamma C_{L}
\end{aligned}
$$

The upper partial moment of the cost shock is denoted as $\bar{\alpha}\left(\alpha^{*}\right)$. An increase in the MQS when $\alpha^{h}$ remains equal to $\alpha_{H}$ has countervailing effects. On one hand it reduces the amount necessary to recoup the initial investment to establish a reputation through increasing $P_{L}$ in the first term on the right-hand side. On the other hand it inflates the price by increasing the average production cost. This is represented by the final term on the right-hand side.

\subsection{Setting an Optimal Minimum Quality STANDARD}

The traditional literature suggests that intervention in the market to establish an MQS is always justified provided that there are zero enforcement costs. This is because only marginal consumers of the low quality product are priced out the market, and all consumers purchasing higher quality products benefit from a price reduction. Our model does not support such a strong claim because the welfare of consumers patronizing firms with a reputation for high quality may either fall or rise if the MQS is raised. While it is unambiguously true that these consumers benefit because the average expected quality increases (as there may be less cheating, and the magnitude of the cheating diminishes), the consumers may have to pay either higher or lower prices. In a model with cheating, it is possible that overall social welfare may be maximized when the MQS equals $q_{\min }$, which is to say that no intervention is justified, even when enforcement of the standard is costless. Representing individual consumers by subscript $i$, a necessary, but not sufficient, condition for this to happen for a marginal increase in the MQS away from $q_{\min }$ is: 


$$
\sum_{i \in X_{H}}\left[\theta_{i} \frac{\partial\left\{\frac{G\left(\alpha^{*}\right)}{G\left(\alpha^{h}\right)} q_{H}+\left[1-\frac{G\left(\alpha^{*}\right)}{G\left(\alpha^{h}\right)}\right] q_{L}\right\}}{\partial C_{L}}-\frac{\partial P_{H}}{\partial C_{L}}\right] \leq 0
$$

The increase in price needs to exceed the valuation of the increase in expected quality. Rather paradoxically, it is possible that the existence of cheating may actually remove the justification for intervention in the market.

Of course, the amerioration of cheating is not the only motivation for quality regulation. Indeed, it is usually not even a primary motivation for market intervention. Occasionally, there is a paternalistic view that even if some consumers freely and knowledgably choose a low quality product, that the level of quality may be "too low" in society's opinion. For example, the British Royal Society (1983) recommended that some physical product risks are so "intolerable" that they should be ameliorated regardless of cost (even to the extent that some consumers are priced out of the market). In addition, minimum quality standards are promulgated in markets which have characteristics that are not modeled in this paper such as asymmetry in information on quality between producers and consumers, and when a product generates negative externalities to bystanders that are not fully internalized by the legal system.

\section{A NUMERICAL EXAMPLE}

The purpose of the numerical example is to provide the reader with additional insights into the workings of the model, and to illustrate cases where raising the MQS increases the price charged by firms with a reputation for high quality. To make the model as transparent as possible, we take the simplest case and assume that $\underline{v}$ is sufficiently large so as to ensure that all consumers choose to purchase the product. The cost shock will be distributed according to an inverted $\mathrm{v}$ shape around a mean of unity and with a range of $1 \pm \delta$, where $0<\delta<1$. This distribution is illustrated in Figure 5. Initially we will look at large cost shocks with $\delta=0.9$.

We will simplify the calculations by normalizing $q_{\min }$ to zero, $q_{H}$ to unity and $\underline{\theta}$ to zero. We will assume that 10,000 consumers are distributed with a uniform density over a space given by $[\underline{v}, \bar{v}]$ on one axis and $[0, \bar{\theta}]$ on the other axis, where $\bar{\theta}=\$ 13, \underline{v}=\$ 12$, and $\bar{v}=\$ 14$. The cost function will be given by $C(q)=(1-\gamma)(0.5+4 q)+\gamma \alpha(0.5+4 q)$ where $\gamma=0.85$. The discount rate $(r)$ is set to 0.07 . 
FIGURE 5: Distribution of $\alpha$ in the Numerical Examples

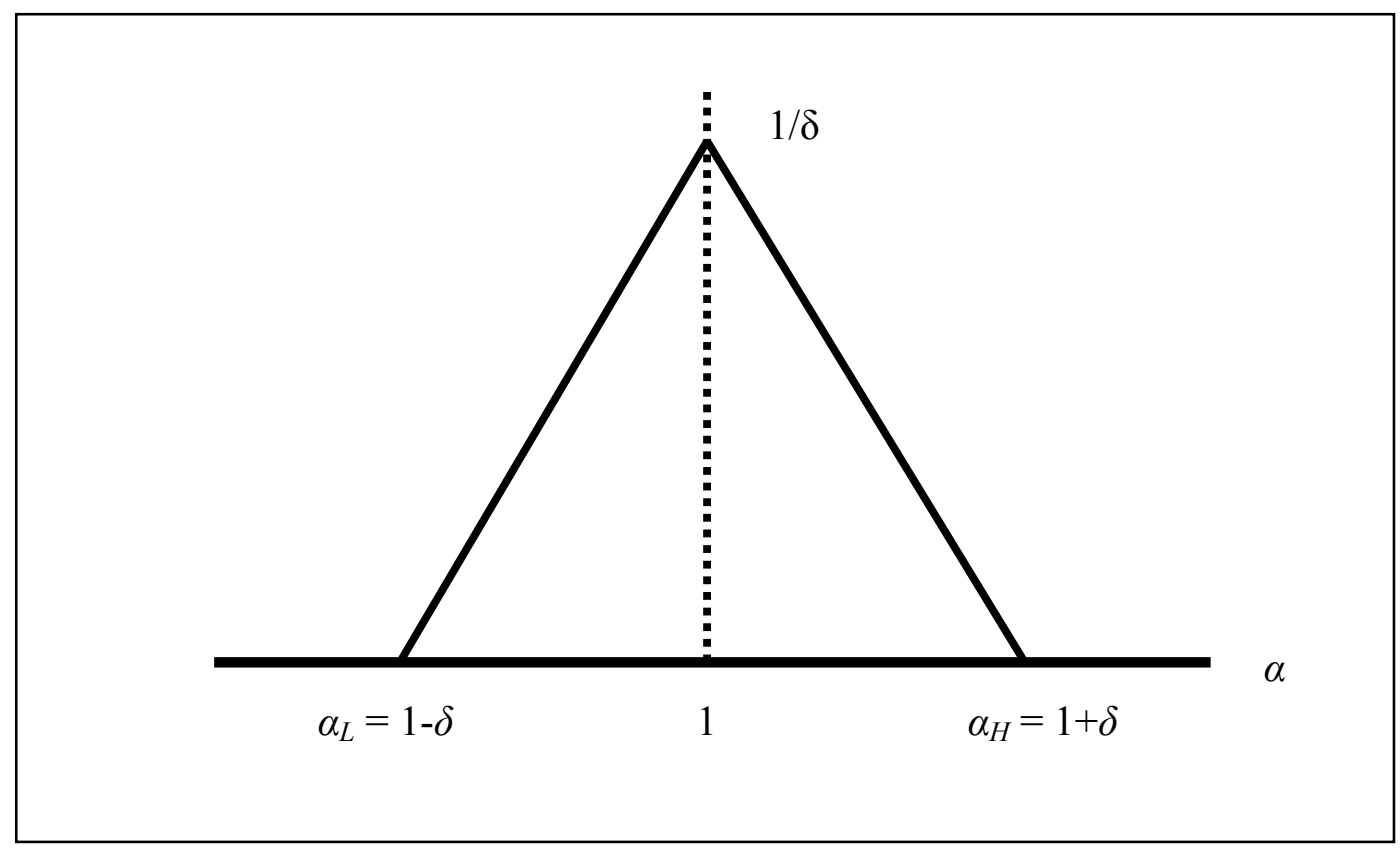

Table 1 shows the equilibrium values for the major variables for discrete levels of $q_{L}$ in increments of 0.1 from $q_{L}=q_{\min }=0$ (when there is no intervention in the market) up to when $q_{L}=q_{H}=1$ (where the MQS is set to $q_{H}$ and only high quality products are sold in the market). When there is no intervention in the market, $\alpha^{*}$ equals 1.05 and $\alpha^{h}$ is at the corner solution and equal to $\alpha_{H}$. Almost half $(44 \%)$ of the firms with a reputation for high quality cheat, but none receive a cost shock large enough that they shut down. Consequently, in equilibrium, consumers patronizing these types of firms will only obtain an expected quality of 0.56 , and pay a price of $\$ 4.33$.

The imposition of an MQS in such a market will have a large effect on the expected quality received by consumers patronizing firms with a reputation for high quality. Even though there is no reduction in the proportion of cheaters among the firms with a reputation for high quality until $q_{L}=0.6$, the quality provided by cheaters improves. Because a large proportion of the units purchased by consumers patronizing firms with a reputation for high quality are supplied by cheaters, the expected quality of the products consumed increases considerably. As the MQS is increased in increments of 0.1 , the expected quality increases from the 0.56 which prevailed without intervention to $0.60,0.65,0.70,0.74$, and 0.78 by the time that the MQS $=0.5$. 
TABLE 1: Numerical Example of a Case where the Price Charged by Firms with a Reputation for High Quality Increases with the MQS

\begin{tabular}{|c|c|c|c|c|c|c|c|c|c|c|c|}
\hline$q_{L}$ & 0 & 0.1 & 0.2 & 0.3 & 0.4 & 0.5 & 0.6 & 0.7 & 0.8 & 0.9 & 1 \\
\hline$\alpha^{*}$ & \multicolumn{11}{|c|}{1.05} \\
\hline $\mathrm{G}\left(\alpha^{*}\right)$ & \multicolumn{11}{|c|}{0.56} \\
\hline \multicolumn{12}{|c|}{ Firms with a reputation for high quality } \\
\hline$\alpha^{h}$ & 1.9 & 1.9 & 1.9 & 1.9 & 1.9 & 1.9 & 1.80 & 1.58 & 1.40 & 1.23 & 1.05 \\
\hline $\mathrm{G}\left(\alpha^{h}\right)$ & 1.0 & 1.0 & 1.0 & 1.0 & 1.0 & 1.0 & 0.99 & 0.94 & 0.84 & 0.72 & 0.56 \\
\hline$P_{H}(\$)$ & 4.33 & 4.35 & 4.37 & 4.38 & 4.40 & 4.42 & 4.44 & 4.45 & 4.39 & 4.27 & 4.03 \\
\hline Expected quality & 0.56 & 0.60 & 0.65 & 0.70 & 0.74 & 0.78 & 0.83 & 0.88 & 0.93 & 0.98 & 1.00 \\
\hline \multicolumn{12}{|c|}{ Firms without a reputation for high quality } \\
\hline$P_{L}(\$)$ & 0.45 & 0.81 & 1.16 & 1.52 & 1.88 & 2.24 & 2.60 & 2.96 & 3.31 & 3.67 & $\mathrm{n} / \mathrm{a}$ \\
\hline$\mu$ & 0.15 & 0.15 & 0.14 & 0.14 & 0.14 & 0.13 & 0.12 & 0.12 & 0.14 & 0.18 & $\mathrm{n} / \mathrm{a}$ \\
\hline Expected quality & 0.15 & 0.24 & 0.32 & 0.40 & 0.48 & 0.56 & 0.65 & 0.74 & 0.83 & 0.92 & $\mathrm{n} / \mathrm{a}$ \\
\hline \multicolumn{12}{|c|}{ Market share of firms with a reputation for high quality (\%) } \\
\hline$\left(1-\theta_{L H}\right) / \bar{\theta}$ & 26 & 25 & 25 & 24 & 23 & 22 & 21 & 20 & 21 & 23 & 100 \\
\hline
\end{tabular}


The downside of the increase in expected quality is that the average cost of production also increases. In our example the price charged by firms with a reputation for high quality increases from $\$ 4.33$ when there is no intervention in the market to $\$ 4.42$ when the MQS $=0.5$. The price continues to increases even when $\alpha^{h}$ becomes interior at an MQS of 0.6 , and equation (28) applies. The equilibrium price reaches a maximum of $\$ 4.45$ when the MQS $=0.7$. It is only for MQS values of 0.8 and greater that the reduction in the premium to recoup the initial investment to establish a reputation exceeds the increased average cost of production, and the price charged by firms with a high quality reputation declines with further increases in the MQS.

The price charged by firms without a reputation increases with the MQS. However, the expected quality received by consumers patronizing these firms also increases. Consequently, at least over some ranges of the MQS, some consumers who originally purchased from firms with a reputation for high quality now find that they are better off switching to patronizing firms without such a reputation. The market share of firms with a high quality reputation, determined in this example by $\left(1-\theta_{L H}\right) / \bar{\theta}$, shrinks from $26 \%$ when there is no intervention in the market to just $20 \%$ when the MQS $=0.8$.

Additional insights into how the magnitude of the cost shock affects the model, and specifically the price charged by firms with a reputation for high quality, can be investigated by reducing $\delta$ to $0.7,0.5,0.3$ and 0.1 . Figure 6 shows the trajectory of $P_{H}$ as the MQS (plotted on the horizontal axis) is increased from 0 to 1 . The price trajectory just described, for $\delta=0.9$, is shown as the line with the star markers. When the line is dashed it means that $\alpha^{h}=\alpha_{H}$, and when it is a solid line it means that $\alpha^{h}$ is interior. The trajectories of price for $\delta=0.7,0.5,0.3$ and 0.1 are shown as the lines marked by the triangles, circles, diamonds and squares, respectively (note that the latter two are very close together).

As the magnitude of the cost shock is reduced, we observe that $P_{H}$ unambiguously increases at all levels of the MQS. The intuition is that as the cost shock variability is reduced, a smaller proportion of the firms with a reputation for high quality cheat. Consequently, the average quality experienced by consumers of firms with a high-quality reputation rises, and with it the expected average cost of production. In addition, as the magnitude of the cost shock declines, it is less likely that an increase in the MQS will lead to an increase in the price for a given level of $\delta$. This graphically supports equation (26) which states that $P_{H}$ will tend to rise in situations where $C_{L}$ is relatively low and the cost shocks are relatively large. 


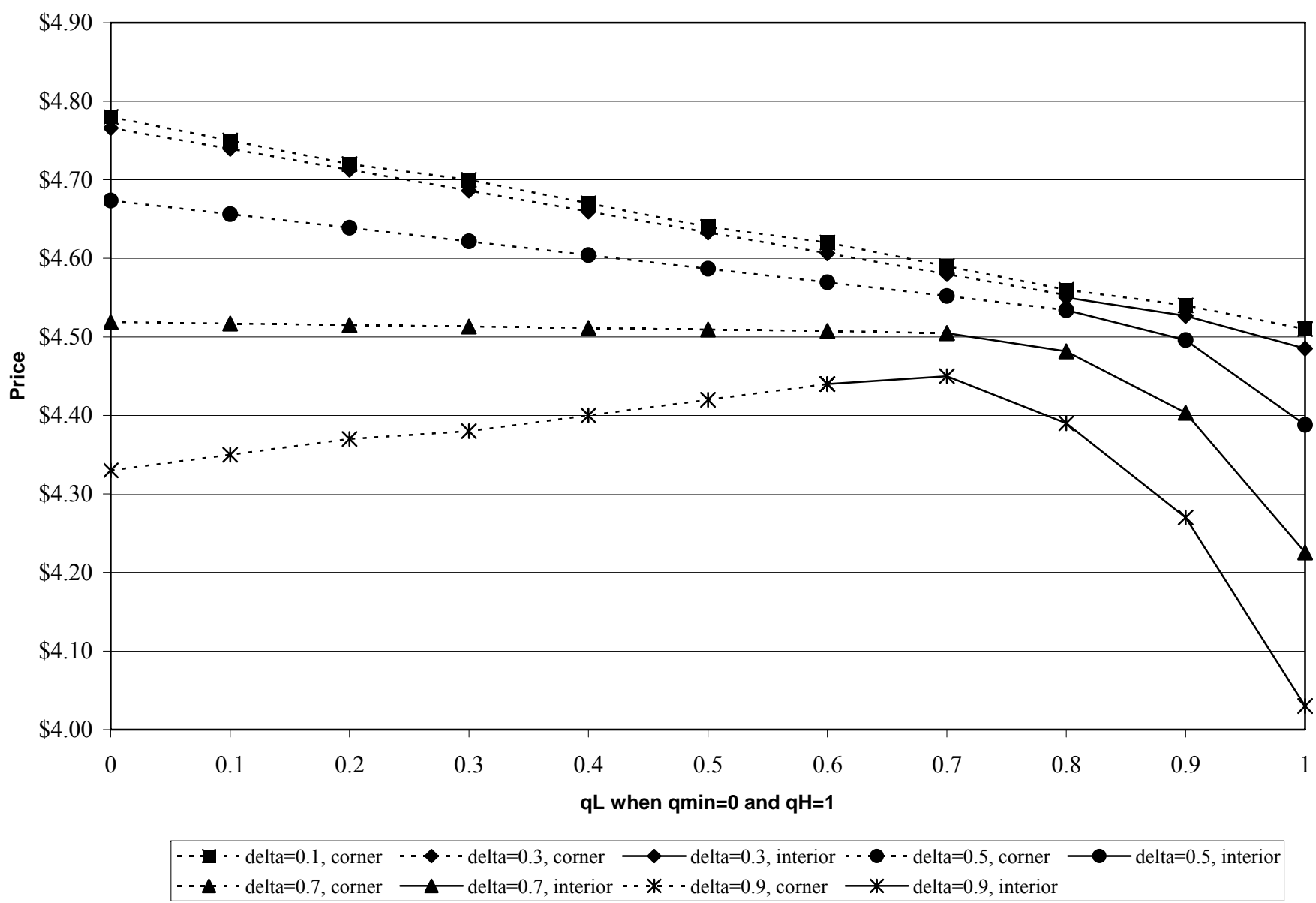

FIGURE 6: Effect of Changing the Magnitude of the Cost Shock on the Price Charged by Firms with a Reputation for High Quality 
Equation (4) tells us that $\alpha^{*}=\alpha_{H}$ when $\alpha_{H}=1 / \gamma$. In this example $\gamma=0.85$. Therefore, there will be a corner solution for $\alpha^{*}$ with no cheating occurring when $\alpha_{H} \leq 1.176$, or $\delta \leq 0.176$. Consequently, the trajectory of price for $\delta=0.1$ will be given by equation (16), and there is an unambiguous decline in the price of the high quality product as the MQS is increased.

\section{IN CONCLUSION}

Our model uses cost shocks to introduce cheating into a competitive model of the formation and destruction of a reputation for producing high quality products. We define a stationary equilibrium in which the expectations of rational consumers are fulfilled, and entry drives expected firm profits to zero. Consumers know the proportion of firms with or without a reputation for quality that are either destroying or establishing their reputation for high quality, but they do not know the identities of the firms who are changing their reputation in the current period.

The traditional literature, in which there is no churning of reputations, finds that establishing, or raising the level of, a minimum quality standard unambiguously benefits consumers of firms with a reputation for supplying high quality. This is because the institution of a standard leads to a reduction in the price charged by firms with a reputation for high quality. In contrast, we show that churning will result in the price charged by such firms either increasing or decreasing. The effect of an MQS on the price of high quality products becomes an empirical rather than a theoretical issue.

An increase in price occurs when one or more of the following conditions exists: (1) the product is relatively inexpensive but the difference in cost between low and high quality is large; (2) the size of the cost shocks is large; and/or (3) there is initially a substantial amount of cheating going on. The first and third conditions will mean that the imposition of a minimum standard will lead to a large increase in the expected quality received by consumers patronizing firms with a reputation for high quality, and an associated large increase in the average cost of production for these firms.

In situations where imposing an MQS leads to an increase in the price of high quality products, it is possible that welfare may be maximized when there is no intervention in the market. For this to occur, the price increase suffered by the consumers of high quality products must exceed their valuation of the increased quality received (because the MQS reduces the incidence and magnitude of the cheating that they suffer). This is most likely to occur when the difference in cost between low and high quality is large, and consumers place a low valuation on 
quality. Rather paradoxically, it is possible that the existence of cheating may actually undermine the usual justifications for intervention in the market.

The practical application of our findings can be illustrated in the context of the restaurant hygiene market that is investigated by Jin and Leslie $(2003,2009)$. Their papers analyze whether the posting of the results of public health inspections affected the quality choices by restaurant owners. Imagine a situation in which the minimum acceptable standards for food hygiene were raised. We find that it is possible that as a consequence restaurants that already exceed the new standard may actually raise their prices.

We should qualify our conclusions with a couple of cautions. The first is that while we demonstrate that is theoretically possible that imposing or raising the MQS may result in the price of high quality products rising, we are not making any claims regarding the likelihood that this will occur in practice. The second is that even if the price of high quality products is observed to rise, it does not necessarily mean that the overall welfare effects of imposing or raising an MQS are negative.

\section{APPENDIX}

Firms with an established reputation for high quality could "pre-commit to cheat" by paying a sunk cost of $(1-\gamma) C_{L}$. These firms are trading off the prospect of a one-time profit against any prospect of maintaining their reputation. The expected profits of a firm pre-committed to cheat $\left(\pi_{P C C}\right)$ are given by:

$$
\pi_{P C C}=G\left(\alpha^{h}\right)\left[P_{H}-\underline{\alpha}\left(\alpha^{h}\right) \gamma C_{L}\right\rfloor-(1-\gamma) C_{L} .
$$

Substituting in equation (10), the definition of $Z\left(\alpha^{h}\right)$, and equations (12), (4) and (7) reveals that $\pi_{P C C}=V_{H}$. In terms of expected profits, firms are indifferent between pre-committing to cheating and entering the period with the intention of maintaining their reputation for high quality. However, these firms were faced with a similar choice when they lacked a reputation. The free entry condition meant that they would expect to earn zero long-run profits whether they had stayed out of the market, decided to offer low quality, or attempted to establish a reputation. The owners of these firms had shown a predisposition to attempt to offer high quality, and we would expect them to continue to do so when faced with the option of pre-committing to cheating after establishing their reputations. 


\section{REFERENCES}

Allen, Franklin. 1984. "Reputation and Product Quality." RAND Journal of Economics, 15(3): 311-327.

Fudenberg, Drew, and David K. Levine. 1992. "Maintaining a Reputation when Strategies are Imperfectly Observed." Review of Economic Studies, 59(3): 561-579.

Gale, Douglas, and Robert W. Rosenthal. 1994. "Price and Quality Cycles for Experience Goods.” RAND Journal of Economics, 25(4): 590-607.

Hörner, Johannes. 2002. "Reputation and Competition." American Economic Review, 92(3): 644-663.

Jin, Ginger Zhe, and Andrew Kato. 2006. "Price, Quality and Reputation: Evidence from an Online Field Experiment." RAND Journal of Economics, 37(4): 983-1005.

Jin, Ginger Zhe, and Phillip Leslie. 2003. "The Effect of Information on Product Quality: Evidence from Restaurant Hygiene Cards." Quarterly Journal of Economics, 118(2): 409-451.

Jin, Ginger Zhe, and Phillip Leslie. 2009. "Reputation Incentives for Restaurant Hygiene.” American Economic Journal (Microeconomics), 1(1): 237-267.

Klein, Benjamin, and Keith E. Leffler. 1981. "The Role of Market Forces in Assuring Contractual Performance." Journal of Political Economy, 89(4): 615-641.

Mailath, George J., and Larry Samuelson. 2001. "Who Wants a Good Reputation?" Review of Economic Studies, 68(2): 415-441.

Napel, Stefan, and Gunnar Oldehaver. 2011. "A Dynamic Perspective on Minimum Quality Standards under Cournot Competition." Journal of Regulatory Economics, 32(1): 29-49.

Nelson, Phillip. 1970. "Information and Consumer Behavior.” Journal of Political Economy, 78(2): 311-329. 
Orosel, Gerhard O., and Klaus G. Zauner. 2011. "Quality Diversity and Prices in Markets for Experience Goods." Journal of Economics and Management Strategy, 20(3): 709-738.

Rogerson, William P. 1983. "Reputation and Product Quality." Bell Journal of Economics, 14(2): 508-516.

Ronnen, Uri. 1991. "Minimum Quality Standards, Fixed Costs, and Competition." RAND Journal of Economics, 22(4): 490-504.

Royal Society. 1983. Risk Assessment: A Group Study Report. London: Royal Society.

Shaked, Avner, and John Sutton. 1982. "Relaxing Price Competition through Product Differentiation." Review of Economic Studies, 49(1): 3-13.

Shapiro, Carl. 1983. "Premiums for High Quality Products as Returns to Reputations." Quarterly Journal of Economics, 98(4): 659-680.

Tadelis, Steven. 1999. "What's in a Name? Reputation as a Tradeable Asset." American Economic Review, 89(3): 548-563.

Tirole, Jean. 1988. The Theory of Industrial Organization. Cambridge, Mass.: MIT Press. 